\title{
PERFORMANCE INVESTIGATION OF A FLAT PLATE COLLECTOR INCORPORATED WITH DIFFERENT TYPE OF MATERIALS
}

\author{
Jaimon Dennis Quadros ${ }^{1}$, Suhas ${ }^{2}$, Vaishak N. L ${ }^{3}$ \\ ${ }^{1,2,3}$ Dept. of Mechanical Engineering, Sahyadri College of Engineering and Management, Adyar, Mangalore, Karnataka, \\ India,jaimonq@gmail.com,poojarysuhas@rocketmail.com,nl_vaishak@rediffmail.com
}

\begin{abstract}
In the present study a performance evaluation is conducted between a normal flat plate collector (Solar Air Heater) and a flat plate collector incorporated with Tin material. The normal flat plate collector consists of a sheet metal placed within the casing and the Tin incorporated flat plate collector consists of Tin material which is stationed in the form of tins along with the sheet metal within the casing The temperature and velocity of air was measured by using a Thermocouple and Thermo- anemometer respectively. The performance evaluation is done on the basis of efficiencies produced by the two flat plate collectors for natural convection and forced convection.
\end{abstract}

Index terms: Tin, Collector, Convection

\section{INTRODUCTION}

Energy is the amount of force or power when applied can move one object from one position to another. Energy can have many forms: kinetic, potential, light, sound, gravitational, elastic, electromagnetic or nuclear. According to the law of conservation of energy, any form of energy can be converted into another form and the total energy will remain the same. With high rates of economic growth and over 15 percent of the world's population, India has become a significant consumer of energy resources. Despite a recent slowing economy, India's energy demand continues to increase. In terms of end-use, energy demand in the transport sector is expected to be particularly high, as vehicle ownership, particularly of four-wheel vehicles, is forecast to increase rapidly once the global economic crisis abates and domestic spending levels resume. India lacks sufficient domestic energy resources and must import much of its growing energy requirements. India is not only experiencing an electricity shortage but is also increasingly dependent on oil imports meet demand. In addition to pursuing domestic oil and gas exploration and production projects, India is also stepping up its natural gas imports, particularly through imports of liquefied natural gas. The country's ability to secure a reliable supply of energy resources at affordable prices will be one of the most important factors in shaping its future energy demand. Coal accounts for more than half of India's total energy consumption followed by oil, which comprises 31 percent of total energy consumption.
$* * *$

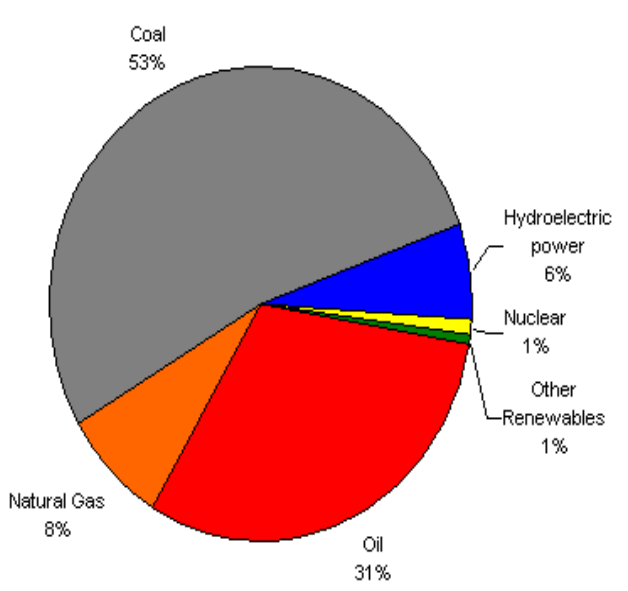

Fig-1: Total energy consumption in India

\section{OBJECTIVE}

The main objective of the present study is to compare the performance of simple flat plate solar air heater with a novel design of solar air heater [1]. The study also aims at improving the efficiency of existing normal solar air heaters.

\section{EXPERIMENTAL SET UP}

The experimental set up primarily consist of casing, tins, Glass cover, Blower attachment, Thermocouples, Anemometer, Stand for inclined support. 


\subsection{Casing}

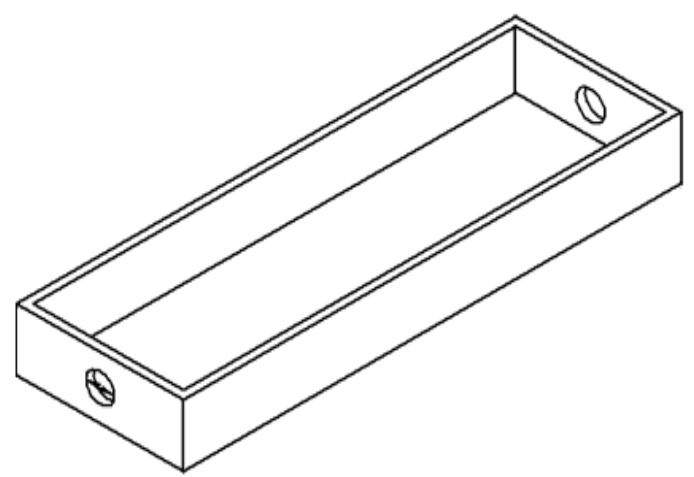

Fig-2: Isometric view of the plywood casing.

The casing is a rigid box made up of Plywood of the following dimension

\section{Length-1200mm}

Breadth-400mm

Height- 150mm

Plywood thickness- 19mm

Two holes of 2.5 inch each are bored at the sides, breadth wise for the inlet and outlet airflow. The insides of the plywood are painted black. The casing is fabricated keeping in mind that there should not be any air leakages due to the presence of voids or gaps in the wooden casing. Plywood has very good weather resistance. Thermal conductivity of plywood is largely dependent on its density and is likely to be in the range of $0.09-0.24 \mathrm{~W} / \mathrm{m}-\mathrm{K}$.

\subsection{Glass Cover}

The glass used here is the regular domestic window pane glass. A single sheet of glass of dimensions $1210 \mathrm{mmX} 410 \mathrm{~mm}$ and $4 \mathrm{~mm}$ thickness is used. Glass easily transmits short wave radiation, which means it poses little interference to the incoming solar radiation.

\subsection{Tin}

Tin was one of the first metals known to man. Throughout ancient history, various cultures recognized the virtues of tin in coatings, alloys and compounds, and use of the metal increased with advancing technology. Tin is relatively unaffected by both water and oxygen at room temperatures. It does not rust, corrode, or react in any other way. The properties of tin are-

Thermal conductivity- $64.0 \mathrm{~W} / \mathrm{m}-\mathrm{C}$

Density- $7.304 \mathrm{e}+3 \mathrm{Kg} / \mathrm{m} 3$

Specific heat- $226.5 \mathrm{~J} / \mathrm{Kg}-\mathrm{C}$

\subsection{Thermocouple}

A thermocouple is a sensor for measuring temperature. It consists of two dissimilar metals joined together at one end. When the junction of the two metals is heated or cooled voltage is produced that can be correlated back to the temperature.

\subsection{Thermo-Anemometer}

Thermo-anemometer is an extremely useful instrument for the measurement of air velocities and air temperature. This instrument can measure accurate air velocity. The instrument comes with a vane type probe, which can measure air velocity in venting air conditioning and heating systems. The main features of the instrument include measurement of air velocities up to $95 \mathrm{~m} / \mathrm{sec}$ and temperature measurement from $0^{\circ} \mathrm{C}$ to $200^{\circ} \mathrm{C}$.

\subsection{Normal Solar Air Heater}

The sheet metal is cut into required dimensions and painted black. It is then placed inside the casing. The glass cover is then fixed on the top or the casing. The casing is painted black and the blower is attached to the inlet side. The set up is then kept on the stand facing south.

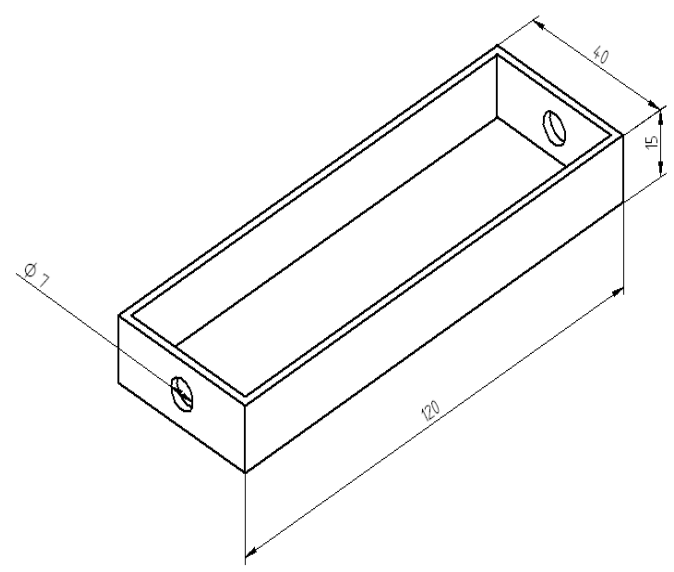

Fig-3: Isometric view of a normal solar air heater.

\subsection{Solar Air Heater with Tins Placed in Series}

The soft drink tins after bonding and painting are glued to the base of the casing in proper alignment giving required tolerance in spacing at the sides. The set up is then painted black. The blower is attached at the inlet side of the casing. The setup is then kept on the stand facing due south. 


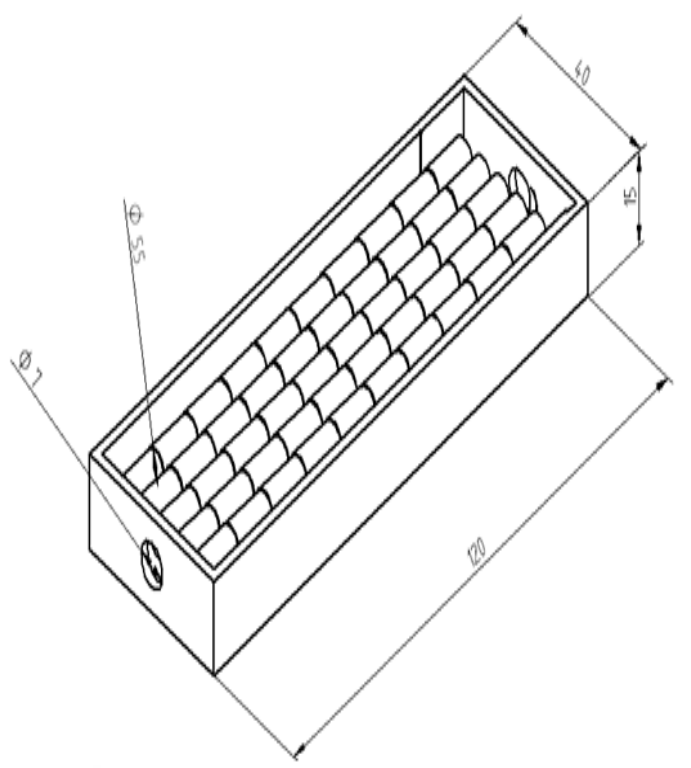

Fig-4: Isometric view of a solar air heater with tins placed in series.

\section{CAlCulation}

The formulation involved in the simulation of Efficiencies mainly includes determination of Mass flow rate, Energy output produced by the Solar flat plate Collector [4]. The energy input is determined from the Solar Insolation Data that is described for a particular area or town or city depending on the intensity of the Sun.

1. Mass flow rate $=$ Density $*$ Area $*$ Velocity

$\mathrm{m}=\rho^{*} \mathrm{~A} * \mathrm{~V}$

$\rho$ is the Density of air $(\mathrm{m} 3 / \mathrm{kg})$

A is the Area of the Flat plate Collector in (m2)

$\mathrm{V}$ is the velocity of air in $(\mathrm{m} / \mathrm{sec})$

2. Solar Insolation Data $=$ Ein $(\mathrm{KW})$

The Solar insolation Data is the energy input obtained by specification of sun's radiation falling onto a particular Area.

3. Energy output $=$ Mass flow rate* Specific heat of air* Difference in Temperature (KW)

$$
\text { Eout }=\mathrm{m} * \mathrm{Cp} *(\mathrm{To}-\mathrm{Ti})
$$

To is the outlet temperature in ${ }^{\circ} \mathrm{C}$

$\mathrm{Ti}$ is the inlet temperature in ${ }^{\circ} \mathrm{C}$

$\mathrm{Cp}$ is the specific heat of air $\left(\mathrm{J} / \mathrm{Kg}^{-}{ }^{\circ} \mathrm{C}\right)$

4. Efficiency= Energy Input / Energy Output

$\eta=($ Ein/ Eout $) * 100$

\section{RESULTS AND DISCUSSION}

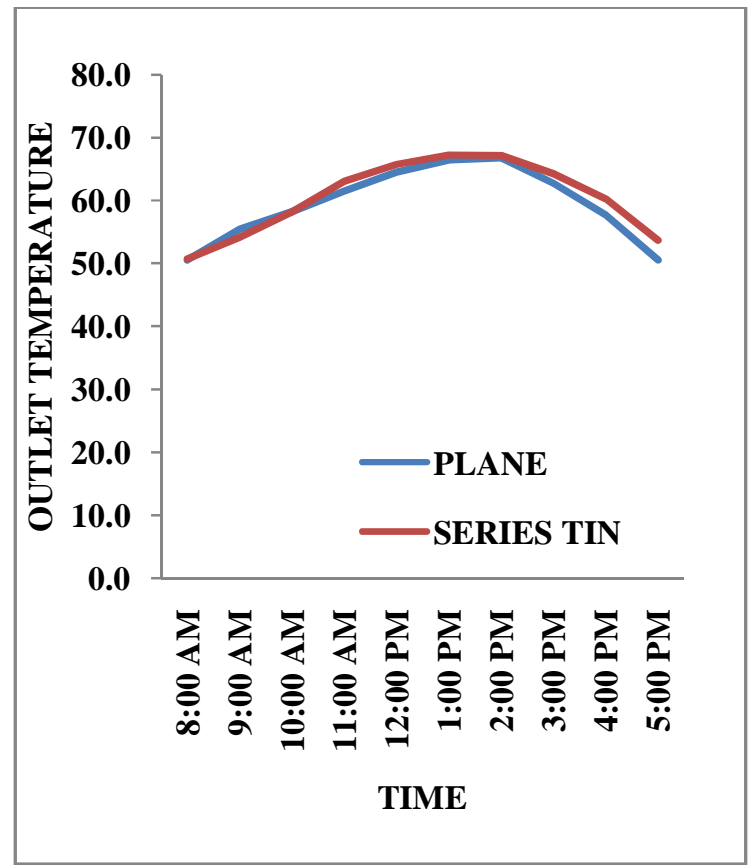

Fig-5: Variation of outlet temperature with respect to time for natural circulation.

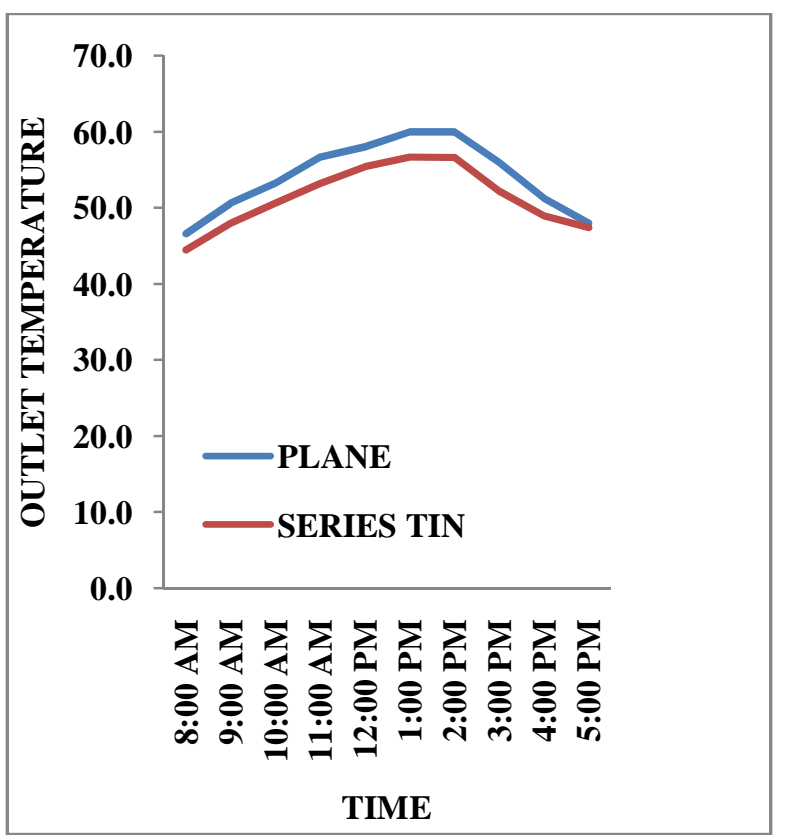

Fig-6: Variation of outlet temperature with respect to time for forced circulation. 


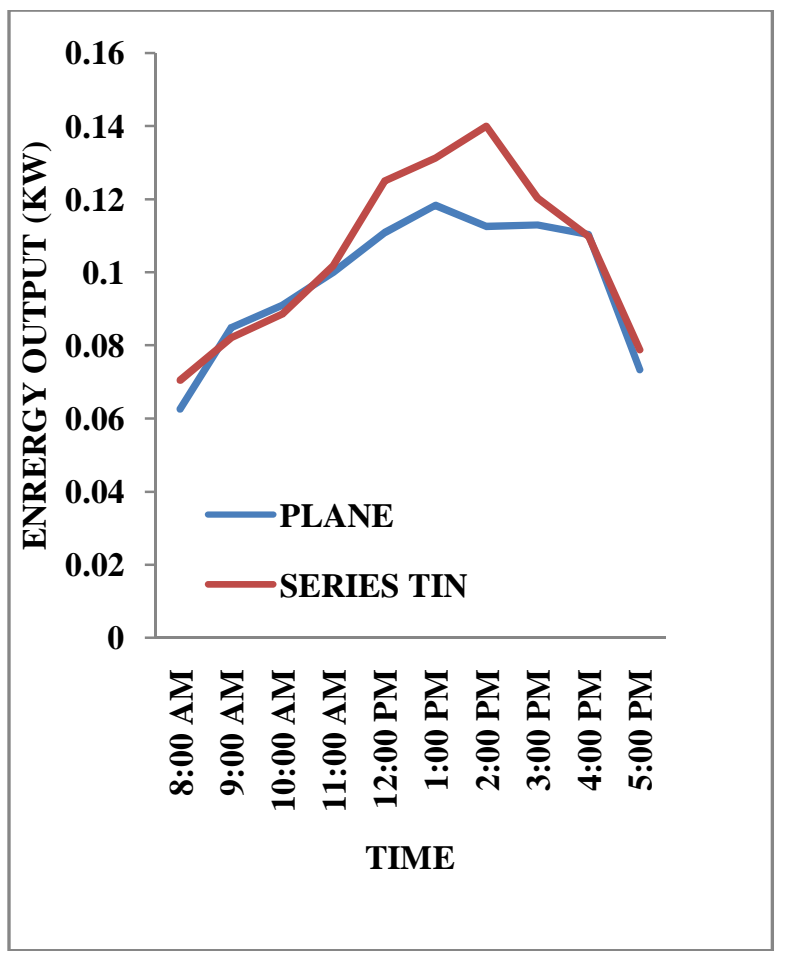

Fig-7: Variation of Energy Output with respect to time for Natural circulation.

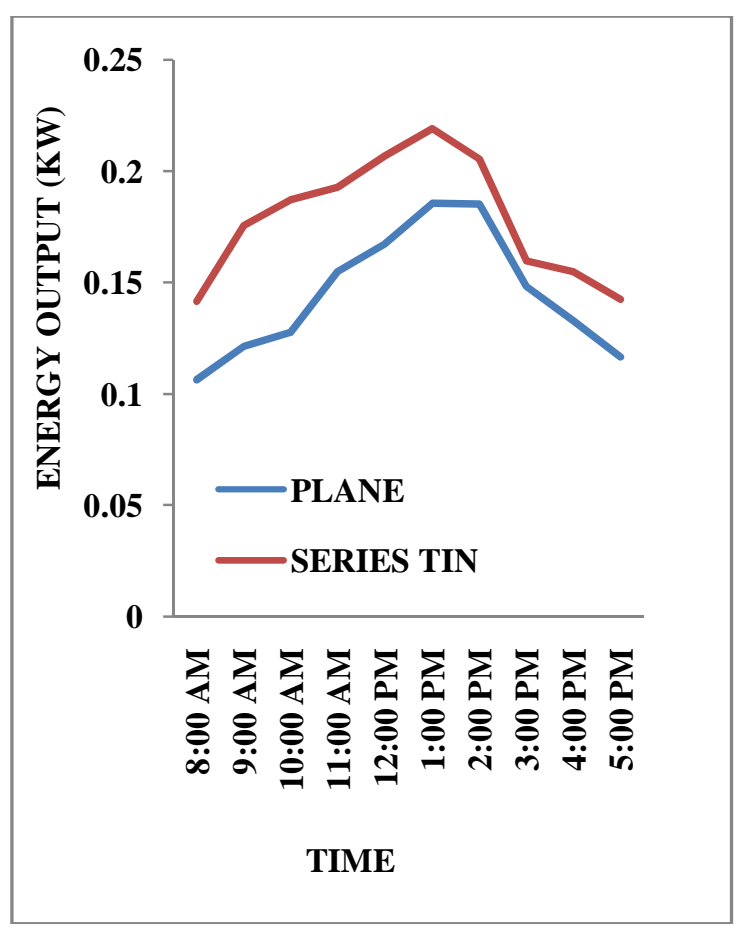

Fig-8: Variation of Energy Output with respect to time for Forced circulation.

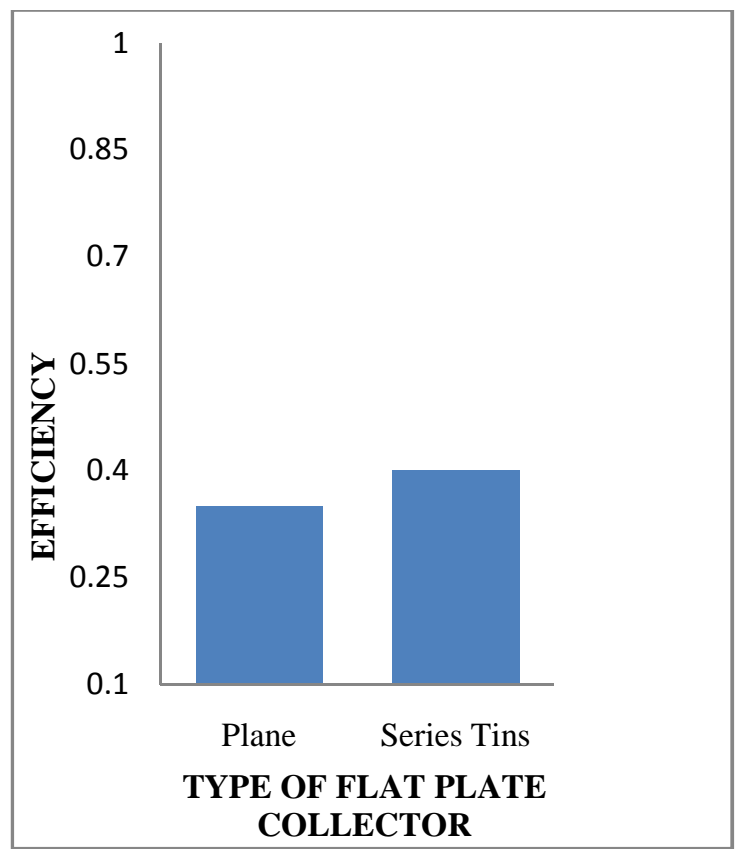

Fig-9: Efficiency comparison of all the flat plate collectors for natural convection.

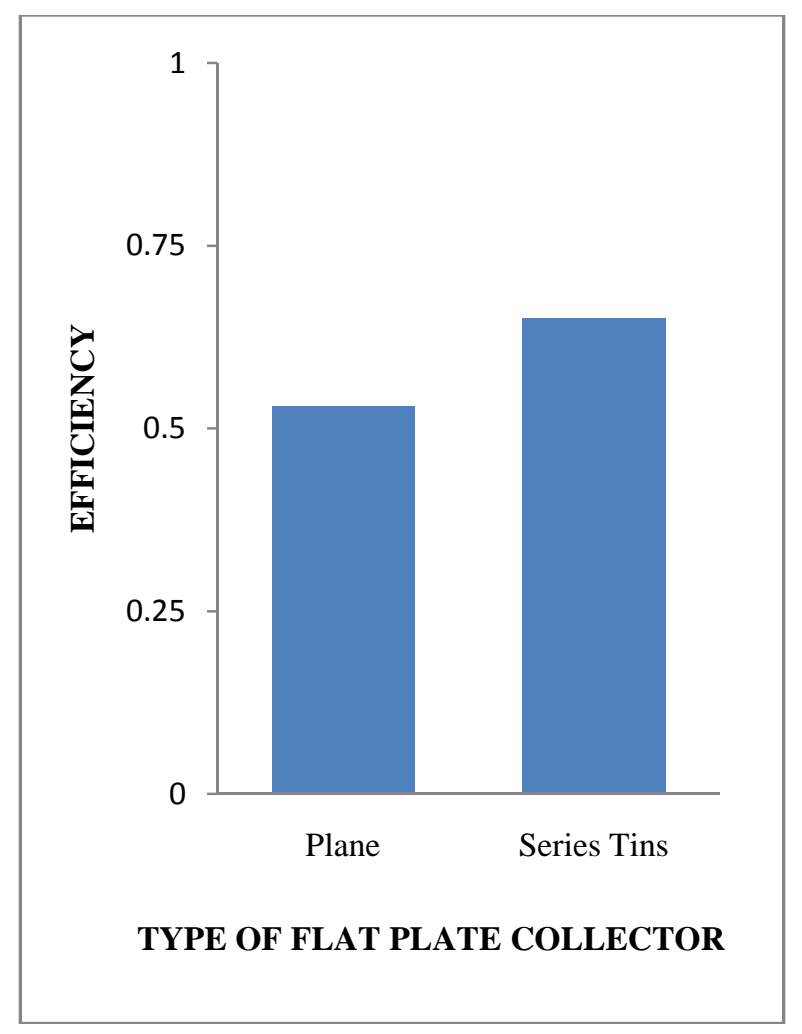

Fig-10: Efficiency comparison of all the flat plate collectors for Forced convection. 


\section{CONCLUSIONS}

The analysis presented above with respect to flat plate heaters brings out some conclusions as discussed below, the experiment conducted on the flat plate collector incorporated with Tin material recorded the highest efficiency for both natural as well as forced convection. This is mainly due to high thermal conductivity of Tin resulting in increased heat transfer co efficient with high temperature at the outlet.

When compared between forced circulation and natural circulation, forced circulation always yields better results. This is due to higher Reynolds number yielding higher mass flow rate in forced circulation, which results in increased heat transfer coefficient.

\section{REFERENCES}

[1] Aboul-Enein, El-Sebaii, S. Ramadan, El-Gohary, "Parametric study of a solar air heater with and without thermal storage for solar drying applications" Renewable Energy, Vol. 21, No. 3, 2000, pp. 505-522.

[2] Karim, Md Azharul, Hawlader, "Performance investigation flat plate V-corrugated and finned Air collectors", Renewable Energy, Vol. 31, No.4, 2006, pp452-470.

[3] Bashria, A. Yousef, Adam, K. Sopian, A. Zaharim and M. Alghoul, "Analysis of Single and Double Passes V-Grooves Solar Collector With and Without Porous Media", Renewable Energy, Vol. 1, No. 2, 2007

[4] H.P. Garg and J. Prakash, "Solar energy fundamentals and applications," first revised edition, Tata Mcgraw-Hill publisher, New Delhi, 2001.

[5] G.D.Rai, "Non conventional energy sources," Khanna Publishers, Fourth edition.

\section{BIOGRAPHIES}

Jaimon Dennis Quadros is working in Sahyadri College of Engineering and Management as an Assistant Professor in the department of Mechanical Engineering. He received the M.Tech degree in Machine Design from Sahyadri college of Engineering and Management, Mangalore affiliated to Visvesvaraya Technological University (VTU) and B.E degree from P.A College of Engineering, Mangalore in 2011. He has presented 2 national conference papers in the field of Aerospace Engineering. His areas of interest are Mechanical Vibrations, Strength of Materials and Computational Fluid Dynamics.

Suhas is working in Sahyadri College of Engineering and Management as an Assistant Professor in the department of Mechanical Engineering. He received the M.Tech degree in Machine Design from Sahyadri college of Engineering and Management (SCEM), Mangalore affiliated to Visvesvaraya Technological University (VTU), in 2013 and B.E degree from Adichunchanagiri Institute of Technology, Chikmagalur in 2011. His areas of interest are Mechanical Vibrations and Mechanics of Materials.

Vaishak N L is working in Sahyadri College of Engineering and Management as Assistant Professor in the department of Mechanical Engineering. He received the M-Tech degree in Industrial Automation and Robotics in Srinivas Institute of Technology, Mangalore from Visvesvaraya Technological University and B.E degree in Vivekananda College of Engineering and Technology Puttur in 2008. He had presented 3 national conference and one international conference papers in the field of robotics. He also published two international journal papers in the field of Automation and Robotics. He is an active member of ISTE. His area of interest is total quality management in the preventive maintenance (in processing industry) and soft automation. 